
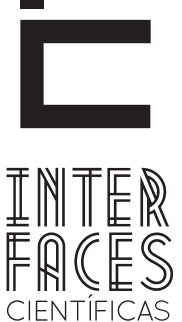

DIREITO

\title{
LEI 8666/93: INFLUÊNCIA DA CONTRATAÇÃO PELO MENOR PREÇO NA QUALIDADE DOS PRODUTOS ENTREGUES
}

\section{RESUMO}

Este artigo tem como objetivo estudar o impacto da Lei 8666/1993 nas licitações de obras de engenharia em um órgão público da administração do Estado do Rio Grande do Sul, Brasil e avaliar a problemática da contratação de obras públicas pelo critério de menor preço, sem levar em conta a capacidade técnica das empresas. Procedimento corriqueiro em todo o território nacional, para uma suposta agilidade na hora das contratações, as quais nem sempre resultam em obras de qualidade. Aliado a isto se tem a deficiência do setor público que desenvolve projetos básicos com informações muitas vezes insuficientes para a contratação dos serviços, desde a compra simples de folhas de papel até a contratação de obras de engenharia complexas. Foram analisadas 24 obras executadas em 3 anos de trabalho sempre contratadas por licitação, utilizando o critério de menor preço global. A citada legislação contempla critérios de técnica e preço, onde além do menor preço global, temos também, a análise da capacidade técnica das empresas. Esta modalidade restringe a contratação de obras públicas a empresas que comprovam realmente que têm condições de entregar uma obra de qualidade. Sem levar em conta a técnica, os órgãos públicos em sua maioria contratam por menor preço. Não tendo como realizar uma análise estruturante das planilhas de preço, não é possível saber se o produto terá a qualidade desejada. Pois a classificação se dá somente pelo valor global, com percentuais limites para tornar uma obra exequível ou inexequível. Percebe-se então, a proble- 
mática da aplicação de uma mesma legislação, genérica, a uma ampla gama de produtos e serviços. Ao se analisar uma legislação que serve tanto para comprar material de escritório como para contratar uma obra milionária percebe-se a necessidade de se elaborar uma lei específica para o setor da construção civil, analisando toda a história pregressa das empresas e reavaliar toda a burocracia de um sistema público regido por tal instrumento.

\section{PALAVRAS-CHAVE}

Lei 8666/1993. Licitações. Obras Públicas. Menor Preço.

\section{ABSTRACT}

This article aims to study the impact of Law 8666/1993 in procurement of engineering works in a public body of the State Administration of Rio Grande do Sul, Brazil and assess the issue of procurement of public works by the criterion of lowest price, without take into account the expertise of companies. Trivial procedure throughout the national territory for an alleged agility at the time of contracting which do not always result in quality works. Allied to this has been the failure of the public sector that develops with basic information is often insufficient for hiring of services, from simple buying sheets of paper to the contracting of works of complex engineering projects. 24 works executed in 3 years of work always contracted by bidding using the criterion of lowest overall price were analyzed. The said legislation includes technical and price criteria, where besides the lowest overall price, we also analyze the technical capabilities of companies. This mode restricts the hiring of public works companies that really prove that is able to deliver a quality workmanship. Without taking into account technical, public bodies mostly hired by lowest price. Not having to perform a structural analysis of price sheets, it is not possible to know if the product will have the desired quality. Because the classification is given only by the global value with percentage limits to make an enforceable or unenforceable work. It can be seen, the problem of applying the same law, generic, a wide range of products and services. When analyzing legislation that serves both to buy office supplies and to hire an expensive project realizes the need to develop a specific law for the construction industry by analyzing the entire previous history of the companies and reevaluate all the bureaucracy of a public system governed by this instrument.

\section{KEYWORDS}

Law 8666/1993. Bids. Public Works. Lower Price. 


\section{RESUMEN}

Este artículo tiene como objetivo estudiar el impacto de la Ley 8666/1993 en la contratación de las obras de ingeniería en un organismo público de la Administración del Estado de Rio Grande do Sul, Brasil y evaluar el tema de la contratación de obras públicas por el criterio del precio más bajo, sin tener en cuenta la experiencia de las empresas. Procedimiento trivial en todo el territorio nacional bajo la argumentación de la presunto agilidad en el momento de la contratación, que no siempre da lugar a obras de calidad. Junto a eso se añade el fracaso del sector público, que se desarrolla con información básica, y a menudo es insuficiente para la contratación de los servicios, a partir de láminas de compra simples de papel para la contratación de las obras de los proyectos de ingeniería complejos. Se analizaron 24 trabajos ejecutados en 3 años, siempre contratado por licitación con el criterio de más bajo precio en general. Dicha legislación incluye criterios técnicos y de precios, donde, además el precio total más bajo, también analizamos las capacidades técnicas de las empresas. Este modo restringe la contratación de empresas públicas que realmente prueban ser capa-

\section{INTRODUÇÃO}

No que diz respeito à contratação de empresas do setor de construção civil para executar obras públicas no Brasil, sejam elas de pequeno, médio ou grande porte, sempre é um tema muito polêmico. Todos os escândalos de corrupção expostos na mídia atual e desde o passado mostram o processo como foco de fraudes, favorecimentos e desvio de verbas públicas. ces de realizar un trabajo de calidad. Y todo eso sin llevar en cuenta aspectos técnicos, los organismos públicos suelen contratar por un precio más bajo. Al no tener que realizar un análisis estructural de las hojas de precios, no es posible saber si el producto tendrá la calidad deseada. Pues la clasificación está dada sólo por el valor global con límites porcentuales para hacer un trabajo ejecutable o no ejecutable. Se puede ver, el problema de la aplicación de la misma ley, una amplia gama de productos y servicios. Al analizar la legislación que a la vez, sirve tanto para comprar suministros de oficina como para contratar a un costoso proyecto. Frente a la situación, se ve la necesidad de elaborar una ley específica para el sector de la construcción, mediante un análisis de toda la historia anterior de las empresas y reevaluar toda la burocracia de un sistema público regulado por la presente instrumento.

\section{PALABRAS CLAVE}

Ley 8666/1993. Las ofertas. Las obras públicas. Precio bajo.
Segundo Tisaka (2013), a Lei $n^{0} 8666 / 1993$ foi aprovada em junho de 1993, num ambiente de grande clamor público contra o governo federal, diante de escandalosos casos de superfaturamento de obras públicas e favorecimento de algumas empresas ligadas a certos políticos, e violenta pressão da mídia junto ao Congresso Nacional para aprovar uma lei que impedisse essa prática. A ideia central 
e simplista para acabar com a corrupção era tirar do administrador público qualquer possibilidade de decisão sobre a melhor solução técnica e econômica, tornando-a totalmente rígida, numa nova visão distorcida do interesse público.

0 presente artigo tem como objetivo analisar o efeito destes fatores na realidade de um órgão público, expondo os resultados de três anos de trabalho em vinte e quatro obras realizadas sempre com a contratação realizada por licitação, utilizando o critério de menor preço global.

0 estudo de caso foi realizado com base no período de $1^{\circ}$ de janeiro de 2010 até 31 de dezembro de 2013. As obras foram analisadas desde sua contratação, execução, cumprimento de prazos, valores orçados e valores licitados, e a qualidade do serviço entregue. Dentro deste prazo todas as obras, concluídas ou não, foram contabilizadas, inclusive as iniciadas antes de $1^{\circ}$ de janeiro de 2011, pois o objetivo é a análise quanto à entrega das obras.

Dentro desta análise foram revisados os processos das obras quanto a pareceres sobre a execução e fiscalização, notificações às empresas, rescisões contratuais, termos de recebimento de obras e aditivos de prazo e valores.

Todas as obras em questão foram contratadas por licitação seguindo os critérios de menor preço global, e todas ficaram dentro do percentual de redução de valor previsto na lei $8666 / 93$ que é de $30 \%$ abaixo do preço do objeto.

\section{DESENVOLVIMENTO}

Segundo o engenheiro Maçahico Tisaka (2013) há um problema que é o que trata da desclassificação de propostas por inexequibilidade de preços (art. 48), quando o licitante apresentar preços inferiores a $70 \%$ do orçamento do órgão ou $80 \%$ da média dos propo- nentes, o que for menor o que pode levar a descontos de mais de $40 \%$ nos preços estimativos do órgão.

Esse percentual estabelecido não tem nenhuma base técnica ou estatística ou até de racionalidade e acabou se tornando um fator de desagregação da capacidade produtiva do setor de construção civil pública do país e uma injustiça para aqueles que pretendem manter um padrão de preços e qualidade compatível com as exigências do mercado e da população.

Os agentes públicos encarregados pelas licitações, cônscio de suas responsabilidades por uma boa gestão de obras públicas, nada podem fazer mesmo sabendo que determinada empresa costumeiramente problemática e inidônea sob o ponto de vista de cumprimento de suas obrigações técnicas ou administrativas, continuar vencendo as licitações, correndo até risco de serem condenados injustamente por improbidade administrativa pelos órgãos de fiscalização e controle.

Toda esta problemática envolve não só a contratação de empresas de construção civil como toda e qualquer contratação ou compra de materiais de quaisquer que sejam as finalidades. Como diz o eng. Edemar de Souza Amorim (2013, n.p.) em seu artigo para a revista Engenharia:

Para se adquirir qualquer coisa, serviço ou obra, são necessárias várias especificações rigorosamente precisas, do que se quer comprar e de que forma deve ser entregue. Na medida em que os produtos e serviços a serem comprados se tornam mais complexos, mais sofisticada será a operação.

Deste modo, e no intuito de coibir esse tipo de ação, foi editada a lei ora em questão, a qual, no seu artigo $45 \S 1^{\circ}$ alínea I, impõe a obrigatoriedade na contratação da proposta pelo menor preço. Contudo, esta mesma lei possibilitou a contratação pelas modalidades técnica e técnica e preço, mas tal procedimento, entretanto, ficou extremamente restringido, como pode ser constado em simples leitura do caput do artigo $46, \mathrm{c} / \mathrm{c}$ o seu $\S 3^{\circ}$, in verbis: 
Art. 46. Os tipos de licitação "melhor técnica" ou "técnica e preço" serão utilizados exclusivamente para serviços de natureza predominantemente intelectual, em especial na elaboração de projetos, cálculos, fiscalização, supervisão e gerenciamento e de engenharia consultiva em geral e, em particular, para a elaboração de estudos técnicos preliminares e projetos básicos e executivos, ressalvado o disposto no $\S 40$ do artigo anterior. (Redação dada pela Lei no 8.883 , de 1994)

[...]

$\S 30$ Excepcionalmente, os tipos de licitação previstos neste artigo poderão ser adotados, por autorização expressa e mediante justificativa circunstanciada da maior autoridade da Administração promotora constante do ato convocatório, para fornecimento de bens e execução de obras ou prestação de serviços de grande vulto majoritariamente dependentes de tecnologia nitidamente sofisticada e de domínio restrito, atestado por autoridades técnicas de reconhecida qualificação, nos casos em que o objeto pretendido admitir soluções alternativas e variações de execução, com repercussões significativas sobre sua qualidade, produtividade, rendimento e durabilidade concretamente mensuráveis, e estas puderem ser adotadas à livre escolha dos licitantes, na conformidade dos critérios objetivamente fixados no ato convocatório. (Grifo nosso).

Como se constata do dispositivo transcrito supra, este não leva em conta fatores como capacidade técnica e quadro de funcionários da empresa, histórico desta na prestação de serviços públicos de qualidade, sua estrutura física e, principalmente sua capacidade de execução em face da quantidade de contratos cujas obras estão em andamento, tanto com clientes do setor público como do setor privado e que comprometem o seu capital, e a sua capacidade de conclusão dos contratos em execução.

Partindo do pressuposto de que uma especificação bem feita bastaria para se adquirir um produto de qualidade ou de se executar uma obra segundo o padrão de qualidade exigido. Mas na prática não é isso que acontece, pois existem vários fabricantes de produtos de escritório, por exemplo, que se enquadram nas especificações, mas oferecem produtos de baixa qualidade. Assim como existem boas e más empresas de construção que se enquadram no padrão exigido pelos órgãos públicos, possuem toda a documentação exigida, mas o produto final nem sempre tem a mesma qualidade.

Ainda segundo Amorim (2013), a redação de regulamentos e leis ao longo do tempo, com base nas experiências bem ou mal sucedidas, é uma das maneiras de se aplicar os conhecimentos adquiridos no aperfeiçoamento dos processos de compras e contratações. Dessa forma as entidades públicas e as empresas privadas foram consolidando suas leis e/ ou regulamentos, buscando minimizar os problemas decorrentes de falhas nas contratações.

No setor público brasileiro, em geral, as escolhas de fornecedores, de obras, de serviços e de bens são regidas pela Lei $n^{0} 8.666 / 93$, que desde sua entrada em vigor está provocando um desmoronamento do sistema de contratações de obras e serviços, afetando as empresas e o mercado, de tal monta que cada licitação se tornou um problema mais jurídico do que técnico, atrasando enormemente os programas governamentais e, consequentemente, a contratação, na maioria das vezes, de empresas sem condições de fazer a obra com a qualidade e prazos desejados.

O que ocorre no setor da construção civil, principalmente nas licitações de obras públicas é uma falha de todo o sistema, partindo da própria Lei $n^{\circ}$ 8.666/1993 que dispõe que as contratações devem ser feitas pelo menor preço global de execução, passando pelos projetos básicos e estudos preliminares, orçamentos, cadastros das empresas e pela burocracia e responsabilidades fiscais exigidas de quem lida com verba pública.

Um processo licitatório de determinada obra não pode acontecer sem um projeto básico sobre o qual se elaborará um levantamento de custos para sua execução. Sem isso não se tem ideia do montante de verba a reservar para concretizar tal construção.

Dentro dos elementos técnicos para a licitação está a planilha orçamentária que serve como base 
para a destinação da verba e é a referência das empresas para elaborarem suas propostas. Segundo o eng. Maçahico Tisaka (2013, n.p.):

Os órgãos de administração do Estado se valem de "cadernos de preços" dos insumos utilizados na construção civil, obtidos através de pesquisas periódicas de preços de mercado realizadas por empresas especializadas, privadas ou do governo, para compor os preços unitários dos serviços a serem realizados.Os preços dos materiais e de equipamentos (aluguel) pesquisados, dependendo da época ou da região podem ter uma margem de erro variadas para cada item pesquisado, porém, de um modo geral, ao preços podem variar em torno de $10 \%$ para mais ou para menos. A mão de obra que é o outro insumo não apresenta nenhuma variação, pois em geral são adotados os pisos salariais para cada categoria de trabalhador.

Somam-se nos preços médios dos serviços os encargos sociais e os Benefícios e Despesas Indiretas (BDI) e se tem o valor estimado para construção (preço e não custo) da obra em questão. Com este orçamento em mãos as empresas elaboram suas propostas que, segundo a Lei nº 8.666/1993 (BRASIL,1993), no artigo 48, dispõe que:

Serão desclassificadas:

I - as propostas que não atendam às exigências do ato convocatório da licitação;

II - as propostas com preços excessivos ou manifestamente inexeqüíveis.

[...]

II - propostas com valor global superior ao limite estabelecido ou com preços manifestamente inexeqüiveis, assim considerados aqueles que não venham a ter demonstrada sua viabilidade através de documentação que comprove que os custos dos insumos são coerentes com os de mercado e que os coeficientes de produtividade são compatíveis com a execução do objeto do contrato, condições estas necessariamente especificadas no ato convocatório da licitação. (Redação dada pela Lei nº 8.883, de 1994)

[...]

$\S 1^{\circ}$ Para os efeitos do disposto no inciso II deste artigo consideram-se manifestamente inexeqüíveis, no caso de licitações de menor preço para obras e serviços de engenharia, as propostas cujos valores sejam inferiores a $70 \%$ (setenta por cento) do menor dos seguintes valores: (Incluído pela Lei nº 9.648, de 1998) a) média aritmética dos valores das propostas superiores a $50 \%$ (cinqüenta por cento) do valor orçado pela administração, ou (Incluído pela Lei nº 9.648, de 1998) b) valor orçado pela administração. (Incluído pela Lei no 9.648 , de 1998).

Conclui-se assim que o valor elaborado pelo órgão público, chamado de Preço do Objeto (PO) tem uma variação média de valor real de $10 \%$ em função de variações de mercado, assim, podemos considerar uma obra exequível se estiver dentro destes limites. A Lei diz que o percentual a ser considerado para isso é de até $30 \%$ abaixo do Preço do Objeto, o que faz com que na maioria das vezes se contrate uma empresa por um valor abaixo do que o mercado considera viável. Somamos a isto a recorrente existência de falhas na elaboração dos elementos técnicos, temos um cenário para o fracasso da referida contratação.

A segunda questão é com relação aos critérios de desclassificação por inexequibilidade da proposta de preços que permitem descontos de mais de $30 \%$ podendo chegar a metade do orçamento estimativo do órgão. A permissão desse exagerado nível de descontos não obedece a nenhum critério técnico ou estatístico e foi baseado no pressuposto de que os lucros das empresas de construção são elevadíssimos, quando na realidade a própria Receita Federal estabelece o lucro em $8 \%$ que é a base de cálculo do IRPJ e a maioria dos órgãos públicos estabelecem no cálculo do BDI a previsão de lucro em torno de $8,0 \%$ na média. Esse elevado percentual considerado fora da realidade, tem propiciado aos incautos e aventureiros, desprovidos do devido preparo no cálculo de orçamentos de obras, a possibilidade de mergulhar nos preços das suas propostas beneficiando-se do critério de menor preço para ganhar a obra, com graves conseqüências, previsíveis para a conclusão adequada das obras, alijando do mercado empresas sérias e tradicionais, gerando elevados prejuízos para o erário público e para a sociedade que é o seu principal beneficiário.

0 grande equívoco cometido pelos parlamentares da época é a falsa interpretação do conceito do BDI que naquela época, pairava em torno de 40,0\%, imaginando, como ainda alguns imaginam, que BDI é sinônimo de lucro, quando na realidade o lucro é estimado em cerca de $8,0 \%$ à $10, .0 \%$, sendo o restante tributos obrigatórios mais uma série de despesas indiretas imprescindíveis para a execução de uma obra. (TISAKA, 2013, n.p.) 
No processo licitatório as empresas apresentam suas propostas que são compostas de duas etapas, a de habilitação onde a empresa apresenta sua documentação técnica e administrativa, mostrando que está em condições de ser contratada pelo órgão público. E a proposta financeira onde mostra por qual valor ela pode executar o que está sendo pedido no edital.

Já na fase de habilitação podemos observar que a lei não menciona qualquer fator relacionado ao histórico da empresa no que diz respeito à qualidade dos serviços prestados, se a empresa teve muitos contratos rescindidos, se há algum apontamento por algum órgão de fiscalização, ou se a empresa já tem um número de contratos vigentes que comprometa o capital financeiro e a estrutura física, dificultando assim a execução do serviço no prazo adequado. As empresas simplesmente são habilitadas pela sua situação no momento da licitação, se não possuem débitos trabalhistas, ou de tributos municipais, estaduais ou federais.

A exigência de um referencial técnico é feita apenas pela apresentação de atestados de capacidade técnica, chancelados pelos conselhos competentes, de que algum profissional que pertence (ou pertencia) ao quadro da empresa naquele momento, já executou alguma obra nos mesmos padrões do que está sendo exigido. 0 que não impede deste profissional após o processo licitatório deixar a empresa.

Por outro lado na alínea $X$ do art. 40 da Lei diz textualmente que [...], [...]permitida a fixação de preços máximos e vedados a fixação de preços mínimos [...] donde se depreende que o órgão licitante pode estabelecer um valor máximo acima do orçamento estimado o que é bastante razoável. Aliás, a lei deixou essa brecha até por uma questão de coerência, pois se o orçamento é estimativo e baseado num projeto que ainda é básico ( Art.40 $\S 2^{\mathrm{a}}$ alínea I e II) e ainda sujeito à flutuação dos preços do mercado, é natural que o orçamento do órgão possa apresentar um certo percentual de erros, para baixo ou para cima, como acontece em qualquer pesquisa de preços. Nesse sentido, se o orçamento do órgão é estimativo obtido através de preços médios dos insumos obtidos no mercado e se a Lei admite um determinado desconto nesses preços, é razoável que, sob o ponto de vista estatístico, se admita também um acréscimo de igual percentual. (TISAKA, 2013, n.p.).

Os quadros abaixo demonstram a realidade de três anos de trabalho no setor público, onde se visualiza a execução das obras e a problemática de prazos e valores de licitação.

Quadro 1 - Análise quanto ao prazo contratual

\begin{tabular}{|l|l|l|}
\hline $\begin{array}{l}\text { Obras entregues dentro do prazo } \\
\text { contratual: }\end{array}$ & 16 & $67 \%$ \\
\hline Obras entregues com aditivo de prazo: & 6 & $25 \%$ \\
\hline Obras rescindidas: & 2 & $8 \%$ \\
\hline Total obras: & $\mathbf{2 4}$ & \\
\hline
\end{tabular}

Fonte: Dados da pesquisa.

A deficiência funcional do setor público vem historicamente lançando mão de projetos incompletos, sem detalhamento suficiente e com especificação de materiais e cadernos de encargos muito mal elaborados. Soma-se a isto o fator político que faz com que estes serviços sejam sempre elaborados às pressas para não correr o risco de se perder uma verba que foi destinada de última hora.

Ao analisar o Quadro 1 percebe-se que em 25\% das obras foi solicitado um aditivo de prazo para a conclusão. Isto se faz necessário muitas vezes por falta de planejamento das empresas, mas também por falha dos técnicos que elaboraram o projeto em estipular um prazo adequado para a realização da obra. Nestas solicitações de prazo, as justificativas variam de falta de material no mercado, dificuldade de contratação de mão de obra, condições climáticas até a atraso no pagamento das faturas e descapitalização das empresas. 0 que pode levar a falência da mesma, se a estrutura e o capital financeiro não conseguem 
absorver este possível atraso de pagamento, como ocorreu em 2 obras no período.

Tem-se o impacto visível do problema de contratar por menor preço, muitas vezes se contrata uma empresa sem condições de executar o que é proposto. E não existe previsão legal para que se faça esta análise durante o processo licitatório, a empresa apenas deve estar em dia com seus tributos, possuir um responsável técnico habilitado e capital social suficiente para executar aquela obra, não importando se este capital pode estar comprometido com outros contratos.

Quadro 2 - Análise quanto ao valor licitado

\begin{tabular}{|l|l|l|}
\hline $\begin{array}{l}\text { Obras entregues dentro do valor } \\
\text { contratual: }\end{array}$ & 13 & $54 \%$ \\
\hline Obras entregues com aditivo de valor: & 2 & $8 \%$ \\
\hline $\begin{array}{l}\text { Obras entregues com compatibilização } \\
\text { interna de valores: }\end{array}$ & 7 & $29 \%$ \\
\hline Obras rescindidas: & 2 & $8 \%$ \\
\hline Total obras: & $\mathbf{2 4}$ & \\
\hline
\end{tabular}

Fonte: Dados da pesquisa.

O Quadro 2 reforça esse fato da contratação por menor preço global, aliada com o problema de projetos incompletos e especificações mal elaboradas. Percebe-se que $29 \%$ das obras tiveram uma compatibilização interna de valores que nada mais é do que retirar serviços que não seriam necessários e substituí-los por serviços necessários e que não foram previstos, sem acréscimo no valor contratual. Esta se tornou uma prática recorrente, pois as empresas que tem conhecimento dos valores de mercado, frequentemente solicitam esta compatibilização, pois lançaram mão de valores unitários de determinado material durante o processo licitatório e na hora de executar a obra, este valor está defasado, pois foi reduzido ao limite dos $30 \%$ previstos em lei.
Quadro 3 - Análise quanto á conclusão

\begin{tabular}{|l|l|l|}
\hline $\begin{array}{l}\text { Obras entregues dentro do valor e prazo } \\
\text { contratual: }\end{array}$ & 13 & $54 \%$ \\
\hline $\begin{array}{l}\text { Obras entregues fora do valor e prazo } \\
\text { contratual, ou não entregues: }\end{array}$ & 11 & $46 \%$ \\
\hline Total obras: & $\mathbf{2 4}$ & \\
\hline
\end{tabular}

Fonte: Dados da pesquisa.

Finalmente no Quadro 3 a análise quanto à entrega das obras. Neste quadro percebe-se que pouco mais da metade das obras foram concluídas dentro do prazo e valor contratuais. Ao passo que $46 \%$ das obras precisaram algum tipo de alteração seja de prazo, valores a aditivar ou valores a compatibilizar. Pode-se creditar este resultado a um conjunto de fatores que inicia em um projeto básico com deficiências na especificação dos serviços a serem executados, passando por uma legislação que exige que se contrate a obra em licitação por menor preço global e culminando na execução, muitas vezes, por empresas que não oferecem a qualidade suficiente.

Ao se licitar uma obra por menor preço, leva-se em conta a teórica "melhor utilização de verba pública”, pois quanto mais barata é a obra melhor, se gasta menos dinheiro publico e podemos aplicar o restante em outras coisas. Na prática, este pensamento é uma grande ilusão travada pela burocracia da Lei $n^{0}$ 8.666/93 que prega tal procedimento.

\section{CONCLUSÃO}

Após a análise dos problemas decorrentes de uma lei de licitações que serve para comprar canetas e também serve para contratar uma obra complexa, chega-se à conclusão que deve se aprofundar a análise da legislação para se chegar a um instrumento específico para contratação de obras públicas. Tal lei não deve incidir na mesma prática de contratar obras somente pelo critério de menor preço global, mas sim analisar a obra no conjunto, com todas suas eta- 
pas, preços unitários, cronograma físico-financeiro e, além de toda a documentação de habilitação da empresa, analisar a sua história pregressa, exigindo, para tanto, certidões de outros órgãos públicos, para os quais prestou ou presta serviços análogos, acerca do cumprimento das obrigações contratuais.

De fato, o que se percebe é que as empresas reduzem os seus preços até os limites admitidos pela Lei no 8.666/93 e, depois não têm condições de adimplir os compromissos assumidos, o que acarreta a inexecução contratual.

Uma alternativa viável enquanto não se tenha alteração na legislação vigente, seria a "relativização", ou ampliação, da utilização da contratação por meio da modalidade "melhor técnica e preço" que, conforme previsão legal somente poderá ser utilizada quando a obra a ser edificada prescindir de tecnologia "sofisticada" e "de domínio restrito". Contudo, segundo a Lei, quando não há exigência desse conhecimento restrito e sofisticado essa modalidade de contratação não pode ser utilizada e, nesse sentido, tem sido os reiterados entendimentos dos órgãos de controle da administração pública uma vez que, quando essa excepcionalidade não é observada o gestor, na maioria das vezes, tem problemas na aprovação das contas.

Com efeito, deve ser reavaliado todo um sistema público, burocrático, que é regido por uma lei muito abrangente que não é mais adequada para o uso na construção civil, e que em face dos seus entraves acaba por gerar maiores prejuízos e gastos à administração pública, haja vista que acarreta a repetição de contratações (ou aditivos a estas), e muitas vezes, inviabiliza a execução contratual, por falta de capacidade técnica e estrutural das empresas vencedoras dos certames licitatórios.

\section{REFERÊNCIAS}

AMORIM, Edemar de Souza. Contratação pelo menor preço: um exemplo de má gestão de recursos públicos. Instituto de Engenharia - Artigos. Disponível em: <www.ie.org.br/site/noticias/print/id_sessao/5/ id_noticias/3200>. Acesso em: 9 mar. 2013.

BRASIL. Lei $\mathbf{n}^{\mathbf{0}} \mathbf{8 6 6 6}$, de 21 de junho de 1993. Regulamenta 0 art. 37, inciso XXI, da Constituição Federal, institui normas para licitações e contratos da Administração Pública e dá outras providências. Diário Oficial da União - Seção 1 - 22/6/1993, 8269p.

MATTOS, Aldo Dórea. Como preparar orçamentos de obras: dicas para orçamentistas, estudos de caso, exemplos. São Paulo: Pini, 2006.

MATTOS, Aldo Dórea. Planejamento e controle de obras. São Paulo: Pini, 2006.

NOGUEIRA, Carnot Leal. Auditoria de qualidade de obras públicas. São Paulo: Pini, 2008.

THOMAZ, Ercio. Tecnologia, gerenciamento e qualidade na construção. São Paulo: Pini, 2001.

TISAKA, Maçahico. Lei de licitações e a polêmica dos critérios de menor preço. Forum da Construção - IBDA. Disponível em: <www.forumdaconstrução.com.br/conteudo.php?a=0\&Cod=401>. Acesso em: 9 mar. 2013.

TISAKA, Maçahico. Lei de licitações o país precisa rever a Lei $\mathbf{n}^{\mathbf{0} 8666 / 93}$. Forum da Construção IBDA. Disponível em: <www.forumdaconstrução. com.br/conteudo.php?a=0\&Cod=401>. Acesso em: 9 mar. 2013. 
